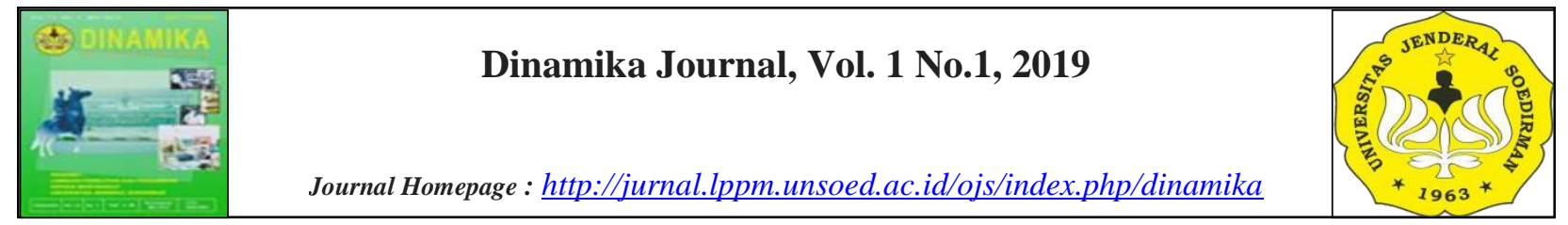

\title{
DILEMATIKA KEBIJAKAN KAPAL CANTRANG DIWILAYAH PANTURA JAWA TENGAH
}

\author{
Mulya* \\ *Stasiun Pengawasan sumber Daya Kelautan dan Perikanan, Direktorat Jenderal \\ Pengawasan Sumber Daya Kelautan dan Perikanan, Cilacap \\ *Corresponding author:almul_tegal@yahoo.com
}

Received 10 May 2019; Accepted 18 June 2019; Available online 28 June 2019

\begin{abstract}
ABSTRAK
Sumberdaya Ikan di Wilayah Pengelolaan Perikanan - Republik Indonesia menunjukkan bahwa Potensi Sumberdaya Ikan Damersal di WPP-RI 712 (Laut Jawa) sebanyak 320,4 ton, dengan Jumlah Tangkapan yang diperbolehkan 246,3 ton dan tingkat pemanfaatan sudah mencapai 0.83 persen, hal ini menunjukan bahwa tingkat pemanfaatannya sudah Fully Exploited (penangkapan penuh). Kebijakan Kementerian Kelautan dan Perikanan yang memberikan perpanjangan waktu operasi kapal Cantrang khususnya di Jawa Tengah menimbulkan dilema, KKP tidak menerbitkan SIUP dan SIPI untuk kapal Cantrang diatas 30 GT sedangkan Provinsi Jawa Tengah menerbitkan SIUP dan SIPI untuk kapal Cantrang dibawah 30 GT, setelah 2 tahun diberi toleransi sejak Permen-KP No.2/2015 diberlakukan kebijakan ini menuai tanggapan positif dan negative masyarakat. Tanggapan positif karena kapal Cantrang dinilai paling produktif dari segi hasil tangkapan dibanding alat tangkap lain, sementara yang negative karena banyak kapal cantrang yang beroperasi tidak sesuai ketentuan, baik dari segi daerah penagkapan ikan maupun ukuran mata jaring yang digunakan termasuk merusak biota laut. Program pemerintah berupa bantuan alat tangkap pengganti Cantrang kepada kelompok nelayan kecil sudah banyak yang disalurkan melalui Dinas Kelautan dan Perikanan Kabupaten / Kota, namun dengan adanya kebijakan perpanjangan waktu operasi kapal Cantrang maka bantuan alat tangkap tersebut tidak digunakan lagi dan seolah tidak bermanfaat. Untuk itu harus ada ketegasan bahwa peraturan pelarangan Cantrang ini sudah harus benar-benar ditegakkan demi upaya kelestarian sumber daya perikanan dan pemanfaatan berkelanjutan.
\end{abstract}

Kata kunci : potensi sumberdaya ikan, dilema, kapal cantrang, Provinsi Jawa Tengah. 


\section{PENDAHULUAN}

Potensi Sumberdaya Kelautan dan Perikanan di Laut Jawa (WPP-RI 712) mengalami eksploitasi yang tinggi, baik dari usaha perikanan, pertambangan maupun industri non perikanan. Jumlah armada kapal penangkap ikan mengalami peningkatan sementara stok sumberdaya ikan stagnan bahkan mengalami penurunan. Tingkat pemanfaatan potensi sumberdaya ikan, khususnya jenis ikan Damersal sudah mencapai 0.83 persen sehingga masuk katagori penangkapan penuh (Fully Exploited), hal ini mendasari kebijakan pemberlakuan pelarangan berbagai alat tangkap terlarang untuk beroperasi di Laut Jawa.

Pemberlakuan kebijakan perpanjangan operasi kapal Cantrang di wilayah Pantura Jawa Tengah menimbulkan gejolak dan reaksi masyarakat, karena jelas sudah dilarang dalam Permen - KP. Nomor 2 / 2015 dan Permen - KP. Nomor 71/2016. Ditambah kapal Cantrang yang tidak sesuai ukuran yang sebenarnya (mark down), khususnya kapal Cantrang yang menggunakan Frezzer sebagai media pendingin ikan, sebelum dilakukan verifikasi dan ukur ulang semua kapal Cantrang berukuran dibawah 30 GT dengan dokumen SIUP dan SIPI dari Provinsi Jawa Tengah, tapi setelah dilakukan verifikasi dan ukur ulang lebih dari 600 unit kapal Cantrang berukuran diatas 30 GT sehingga dokumen SIUP dan SIPI dari Ditjen Perikanan Tangkap - Kementerian Kelautan dan Perikanan. Padahal ukuran kapal sangat mempengaruhi ukuran alat tangkap yang digunakan, kapasitas palka, muatan ikan hasil tangkapan dan daya mesin induk yang digunakan.

Kebijakan perpanjangan ini menjadi dilema karena kapal Cantrang diatas 30 GT tidak dikeluarkan dokumen perizinan berupa SIUP dan SIPI karena alat tangkap Cantrang termasuk yang dilarang. Namun Badan Penanaman Modal Daerah (BPMD) Provinsi Jawa Tengah tetap mengeluarkan SIUP dan SIPI untuk kapal Cantrang dibawah 30 GT dengan dasar arahan Presiden Republik Indonesia dan Surat Menteri Kelautan dan Perikanan nomor : 18 / MEN-KP/I/2018 tanggal 13 Januari 2018 perihal Pemberian Diskresi Perpanjangan Masa Peralihan Alat Penangkap Ikan (API) yang dilarang kepada Pemerintah Daerah Provinsi Jawa Tengah, disatu sisi KKP tetap memperlakukan aturan dan menghendaki agar stok sumberdaya ikan di Laut Jawa terjaga dengan berkurangnya eksploitasi penangkapan ikan, disisi lain Pemda Jawa Tengah tetap mengeluarkan izin penangkapan ikan, hal ini memicu kecemburuan masyarakat nelayan lain karena kapal Cantrang tidak hanya berada di Jawa Tengah tetapi ada di Lampung, Banten dan Jawa Timur, sehingga pemberlakuan peraturan menteri tersebut tidak berlaku secara nasional tapi regional Jawa Tengah.

Kementerian Kelautan dan Perikanan sudah memberi toleransi dan kelonggaran waktu untuk kapal Cantrang selama 2 (dua) tahun untuk beroperasi dan berakhir sampai 31 Desember 2016, ditambah lagi perpanjangan waktu 2 kali 6 bulan sampai 31 Desember 2017 agar pemilik kapal Cantrang ada kesiapan untuk mengganti alat tangkap yang ramah lingkungan, namun sampai akhir tahun 2017 pemilik kapal Cantrang diwilayah Pantura Jawa Tengah dari mulai Rembang, Batang, Pemalang, Tegal dan Brebes belum ada kesiapan secara penuh untuk mengganti alat tangkap pengganti Cantrang karena adanya tarik ulur dan ketidaktegasan penerapan aturan, disatu sisi supaya mengganti alat tangkap ramah lingkungan tetapi disisi lain masih memperbolehkan penggunaan alat tangkap terlarang, sehingga muncul penilaian dan anggapan positif dan negative tentang kebijakan tersebut. Sebagian masyarakat yang mendukung kebijakan beranggapan bahwa Cantrang adalah alat tangkap yang paling produktif dan relative murah dibanding alat tangkap lainnya, sedangkan yang menolak beranggapan bahwa Cantrang termasuk tidak ramah lingkungan karena dapat merusak dan mengganggu keberlanjutan biota laut dan mengancam kepunahan sumberdaya perikanan yang ada. 
Meski berbagai kebijakan dan toleransi perpanjangan diberikan tetapi aksi unjuk rasa dan pengerahan massa untuk menolak pemberlakuan Permen No. 2 /2015 terus dilakukan oleh Nahkoda dan Pemilik Kapal Cantrang, baik di Rembang, Batang maupun di Tegal, mereka menuntut kepada Presiden dan Kementerian Kelautan dan Perikanan agar dilakukan uji petik secara independen untuk memastikan apakah alat tangkap Cantrang termasuk alat tangkap yang merusak dan tidak ramah lingkungan. Juga menuntut agar alat tangkap Cantrang diperbolehkan kembali beroperasi dan dilegalkan secara nasional, pada tanggal 15 Januari 2018 dilakukan dialog antara Presiden Republik Indonesia dengan Aliansi Nelayan Indonesia (ANNI) dan 16 orang perwakilan nelayan Cantrang Jawa Tengah, mulai dari Rembang, Juwana, Batang, Tegal dan Brebes.

\section{METODE PENELETIAN}

Metode penelitian yang dilakukan adalah dengan dasar hasil studi literatur, PermenKP, Surat Edaran dan paparan narasumber dari berbagai pertemuan dan sosialisasi diwilayah Tegal, Brebes dan Pemalang dan bahan bahan dari sumber lain yang berkaitan dengan kebijakan kapal Cantrang, juga hasil pengawasan dan berinteraksi, mewancarai dengan Pemilik kapal, Nahkoda kapal, Anak Buak Kapal, Pengurus kapal Cantrang dilapangan baik di Pelabuhan Kluwut - Brebes, PPP Tegalsari dan PPP Asemdoyong.

\section{HASIL DAN PEMBAHASAN}

Peraturan Menteri Kelautan dan Perikanan nomor : 47 / 2016 tentang Estimasi potensi, jumlah tangkapan yang diperbolehkan, dan tingkat pemanfaatan sumberdaya ikan di WPP-RI menyebutkan bahwa Potensi SDI Laut Jawa (WPP-RI 712) untuk jenis ikan Damersal sebanyak 320,4 ton, dengan jumlah tangkapan yang diperbolehkan 246,3 ton dan tingkat pemanfaatan sudah mencapai 0.83 persen, ini mengindikasikan bahwa Laut Jawa sudah mengalami penangkapan penuh, karena armada kapal penangkap ikan banyak sedangkan sumberdaya ikan terbatas, jumlah kapal di Jawa Tengah ada kl. 24.600 unit kapal dengan berbagi ukuran dan berbagai jenis alat tangkap (DKP Jateng- 2018), luas Laut Jawa hanya 15 persen dari seluruh luas Laut di Indonesia, sedangkan jumlah nelayan penangkap ikan di Jawa ada 35 persen dibanding jumlah seluruh nelayan yang ada di Indonesia (Ditjen Tangkap - 2015). Maka muncul kebijakan pembatasan dan pelarangan kapal dengan alat tangkap terlarang, termasuk Cantrang

Peraturan Menteri Kelautan dan Perikanan Nomor :71/Permen-KP/2016 tentang Jalur Penangkapan Ikan dan Penempatan Alat Penangkapan Ikan (API) di WPP- RI pada pasal 21 ayat (1) disebutkan bahwa "API yang mengganggu dan merusak keberlanjutan sumberdaya ikan merupakan API yang dioperasikan dapat mengganggu kepunahan biota, mengakibatkan kehancuran habitat dan membahayakan keselamatan pengguna.' Pada ayat (2) disebutkan 'API yang mengganggu dan merusak sumberdaya ikan sebagimana pasal 1 adalah : Pukat Tarik (Seine Net), Dogol (Daniesh Seine), Scottish Seine, Pairs Seine, Cantrang dan Lampara Dasar, sehingga API tersebut dilarang beroperasi diseluruh WPPRI sebagaimana tercantum dalam pasal 21 ayat (3) 'Penggunaan API yang mengganggu dan merusak sumberdaya ikan sebagaimana ayat

(1) dilarang dioperasikan disemua jalur penangkapan ikan diseluruh WPP-RI.' peraturan menteri tersebut masih tetap berlaku secara nasional diseluruh Indonesia dan tidak dicabut, namun peraturan tersebut tidak berlaku bagi kapal Cantrang di Provinsi Jawa Tengah, kapal Cantrang Jawa Tengah mendapat perlakuan khusus (lex spesialis) sehingga diperbolehkan beroperasi padahal kapal Cantrang tidak hanya di Jawa Tengah tetapi ada di 
Lampung, Banten dan Jawa Timur. Hal ini menjadi catatan tersendiri mengapa hal ini bisa terjadi juga dalam hal dokumen perizinan kapal Cantrang diatas 30 GT karena tidak ada SIUP dan SIPI sehingga tidak diterbitkan SLO dan SPB, sementara kapal Cantrang dibawah 30 GT tetap dikeluarkan SIUP dan SIPI dari BPMD Provinsi Jawa Tengah sehingga diterbitkan SLO dan SPB.

Dasar kebijakan perpanjangan operasi kapal Cantrang di Provinsi Jawa Tengah adalah arahan Bapak Presiden Republik Indonesia tanggal 17 Januari 2018 di Istana Negara dan surat Menteri Kelautan dan Perikanan nomor : B-91/MEN-KP/II/2018 tanggal 7 Februari 2018 perihal Pemberian Diskresi Perpanjangan Masa Peralihan Alat Penangkap Ikan (API) yang dilarang kepada Pemerintah Daerah Provinsi Jawa Tengah, hal ini menjadi dilema karena diantaranya berisi bahwa Kementerian Kelautan dan Perikanan tidak mencabut Peraturan Menteri Kelautan dan Perikanan Nomor :71/PermenKP/2016 tentang Jalur Penangkapan Ikan dan Penempatan Alat Penangkapan Ikan (API) di WPP- RI. Kementeran Kelautan dan Perikanan tidak akan menerbitkan Surat Izin Usaha Perikanan (SIUP) dan Surat Izin Penangkapan Ikan (SIPI) alat tangkap terlarang lainnya, karena penerbitan SIUP dan SIPI hanya diperuntukan bagi nelayan yang menggunakan alat tangkap tidak dilarang, karena Cantrang termasuk yang dilarang maka tidak diterbitkan SIUP dan SIPI sebelum mereka mengganti dengan alat tangkap yang tidak dilarang, terhadap kapal Cantrang yang akan melaut, Kementerian Kelautan dan Perikanan memberikan dokumen berupa Surat Keterangan Melaut (SKM) berdasarkan Surat Pernyataan Melaut (SPM) yang ditandatangani oleh nahkoda kapal. Pemilik kapal Cantrang yang masih memiliki SIUP lama yang dikeluarkan oleh Provinsi Jawa Tengah dianggap sudah tidak berlaku karena ukuran kapal sudah berubah setelah verifikasi dan ukur ulang. Jumlah kapal Cantrang di Jawa Tengah sesuai data DKP Provinsi Jawa Tengah tahun 2018 sebanyak 1223 unit kapal, setelah diverifkasi dan ukur ulang sebanyak kl. 600 unit kapal berukuran diatas 30 GT.

Kementerian Kelautan dan Perikanan tidak mempersoalkan nelayan cantrang melaut kembali sesuai arahan Bapak Presiden, namun tempat penangkapan ikan (Fishing Ground) yang diperbolehkan hanya di Jalur 2 Pantai Utara Jawa (WPP-RI) 712, tidak untuk WPPRI lainnya.

Tabel 1. Jalur Penangkapan

\begin{tabular}{|c|c|c|}
\hline No. & Jalur Penangkapan & Batasan Wilayah \\
\hline 1. & Jalur I A & $\begin{array}{l}\text { Mulai dari garis pantai sampai } 2 \text { mil dihitung dari } \\
\text { permukaan air laut pada saat surut terendah }\end{array}$ \\
\hline & Jalur I B & Mulai 2 mil sampai 4 mil \\
\hline 2. & Jalur II & $\begin{array}{l}\text { Perairan diluar Jalur I sampai } 12 \text { mil dihitung dari } \\
\text { permukaan air laut pada saat surut terendah }\end{array}$ \\
\hline 3. & Jalur III & $\begin{array}{l}\text { Perairan ZEEI dan diluar Jalur II dihitung dari } \\
\text { permukaan air laut pada saat surut terendah }\end{array}$ \\
\hline
\end{tabular}

Sumber : Permen-KP No.71/2016.

Masyarakat yang mendukung adanya kebijakan tersebut beranggapan bahwa alat tangkap Cantrang adalah pilihan utama yang sudah digunakan sejak tahun 1990 setelah penghapusan alat tangkap Trawl tahun 1985. Dengan berbagai alasan, karena dianggap Cantrang paling produktif hasil tangkapannya, ikan jenis apa saja bisa tertangkap terutama ikan cumi yang punya nilai ekonomi tinggi, mudah dalam pengoperasiannya dengan alat bantu sederhana hanya gardan dan jumlah awak kapal lebih sedikit dibanding purse seine dan harga alat tangkap Cantrang relative lebih murah dibanding alat tangkap lainnya dan mudah dalam perawatannya. 
Sebagian lagi masyarakat menolak kebijakan perpanjangan Cantrang beroperasi lagi yaitu nelayan Purse Seine atau Mini Purse Seine, Gill Net dan Jaring Cumi yang ada diwilayah Pantura Jawa Tengah, mereka beranggapan bahwa Cantrang adalah modifikasi dari mini trawl yang bentuk dan cara pengoperasiannya mirip trawl, hanya beda tidak pakai mulut pembuka jaring (otterboard), pada awalnya hanya untuk kapal kecil berukuran dibawah 10 GT, tapi makin lama ukuran kapal makin besar sehingga mempengaruhi hasil tangkapan kapal lain. Para pemilik kapal, nahkoda dan nelayan non cantrang yang tergabung dalam Paguyuban Nelayan Sejahtera (PNS) pada tanggal 23 Februari 2018 menemui Menteri Kelautan dan Perikanan, mereka memprotes kebijakan Kementerian Kelautan dan Perikanan yang memberikan perpanjangan waktu beroperasi bagi kapal cantrang, alasan mereka karena banyak kapal cantrang yang beroperasi tidak sesuai ketentuan diantaranya melanggar daerah penangkapan ikan, menggunakan mesh size jaring kantong terlalu kecil kurang dari 2 inch sehingga merusak biota laut dan ikan

-ikan kecil, karena potensi sumber daya ikan di Laut Jawa telah menurun drastis akibat penangkapan merusak. Hanya sebagian kecil di bagian timur Indonesia yang masih memiliki kondisi stok ikan bagus karena penangkapan belum masif dan menggunakan pancing dan alat tangkap tradisional lainnya.

Nelayan Cantrang di bawah 10 GT sudah banyak yang dibantu oleh pemerintah untuk mengganti dengan alat tangkap Badong untuk menangkap Rajungan, serta ditambah dengan pelatihan dan atau kredit lunak untuk permodalan dari pihak perbankan. Adanya kebijakan perpanjangan waktu operasi kapal Cantrang maka alat tangkap tersebut tidak digunakan lagi dan tidak bermanfaat karena menggunakan Cantrang lagi, hal ini menjadi dilema, disatu sisi pemerintah mengharapkan agar ganti alat tangkap disisi lain masih tetap menggunakan Cantrang karena masih diperbolehkan.

Untuk itu harus ada ketegasan bahwa peraturan pelarangan Cantrang ini sudah harus benar-benar ditegakkan demi upaya kelestarian sumber daya perikanan dan pemanfaatan berkelanjutan. Peraturan pelarangan Cantrang ini sudah harus benar-benar ditegakkan, demi kepentingan bangsa Indonesia tanpa kecuali. Lemahnya penegakan aturan selama ini harus dibayar mahal oleh pemerintah sekarang, karena banyaknya dampak buruk yang harus diperbaiki. Kerugian pengguna Cantrang, sama sekali tidak seimbang dengan kerugian yang telah dialami oleh masyarakat nelayan yang lain. Kelestarian sumber daya perikanan dan pemanfaatan berkelanjutan untuk kemakmuran mseluruh masyarakat Indonesia yang harus menjadi pertimbangan pertama dan utama.

\section{KESIMPULAN}

Kebijakan perpanjangan operasi kapal Cantrang di Jawa Tengah menimbulkan banyak persoalan dan dilema, mengingat kondisi Laut Jawa yang sudah penuh tangkap dan penurunan stok ikan maka memerlukan kebijakan untuk membatasi dan mengurangi penangkapan ikan yang merusak, sebagai alat tangkap terlarang Cantrang jelas tidak boleh beroperasi di seluruh WPP-RI terkecuali di Jalur II WPP-RI 712 (Laut Jawa), padahal kapal Cantrang juga ada di Lampung, Banten dan Jawa Timur. Sehingga timbul gejolak dan anggapan positif dan negative di masyarakat. Tanggapan positif karena kapal Cantrang dinilai paling produktif dari segi hasil tangkapan dibanding alat tangkap lain, sementara yang negative karena banyak kapal cantrang yang beroperasi tidak sesuai ketentuan, baik dari segi daerah penagkapan ikan maupun ukuran mata jaring yang digunakan termasuk merusak biota laut.

KKP tidak mengeluarkan SIUP dan SIPI untuk kapal Cantrang diatas 30 GT sedangkan Provinsi Jawa Tengah mengeluarkan SIUP dan SIPI untuk kapal dibawah 30 GT, sementara KKP tidak mencabut Permen-KP No.71/2016. KKP berupaya 
memberikan bantuan dengan mengganti alat tangkap Cantrang diganti Badong untuk menangkap Rajungan, serta ditambah dengan pelatihan dan atau kredit lunak untuk permodalan dari pihak perbankan. Namun adanya perpanjangan waktu operasi kapal Cantrang maka alat tangkap tersebut tidak digunakan lagi dan tidak bermanfaat karena menggunakan Cantrang lagi, hal ini menjadi dilema, disatu sisi pemerintah mengharapkan agar ganti alat tangkap disisi lain masih tetap menggunakan Cantrang karena masih diperbolehkan.

\section{SARAN}

Pemerintah harus benar-benar menegakkan aturan pelarangan Cantrang demi upaya kelestarian sumber daya perikanan dan pemanfaatan berkelanjutan. Pengawas Perikanan dan aparat penegak hukum dilaut harus senantiasa melakukan pengawasan aktifitas penangkapan ikan kapal Cantrang agar sesuai ketentuan.

\section{DAFTAR PUSTAKA}

Keputusan Menteri Kelautan Dan Perikanan Republik Indonesia Nomor Kep.06/Men/ 2010 Tentang Alat Penangkapan Ikan Di Wilayah Pengelolaan Perikanan Negara Republik Indonesia.

Keputusan Presiden Republik Indonesia Nomor 39 Tahun 1980 Tentang Penghapusan Jaring Trawl.

Peraturan Menteri Kelautan dan Perikanan Nomor 2 Tahun 2015 Tentang Larangan Penggunaan Alat Penangkapan Ikan Pukat Hela (Trawls) dan Pukat Tarik (Seine Nets).

Peraturan Menteri Kelautan dan Perikanan Nomor 71/Permen-KP/2016 Tentang Tentang Jalur Penangkapan Ikan Dan Penempatan Alat Penangkapan Ikan Dan Alat Bantu Penangkapan Ikan Di Wilayah Pengelolaan Perikanan Negara Republik Indonesia

Rekomendasi Ombudsman Republik Indonesia, (Juni 2015).

Surat Dirjen PSDKP No. 14319/DJPSDKP/IX/2015 (September 2015). 